\title{
Analysis Of Quality Of Life Of Dialysis Patients (Male And Female) With Kidney Disease
}

\author{
Aqeel Haider \\ Department of Social Work \\ University of Karachi \\ Nasreen Aslam Shah \\ Department of Social Work \& Women's Studies \\ University of Pakistan \\ Muhammad Shahid \\ Department of Social Work \\ University of Karachi
}

\begin{abstract}
Focus of the investigation is to get some answers concerning the kidney illness and its effects on the everyday lives of the patients. Mostly patients don't think about the causes and how this illness is influencing and hauling them to finish their life step by step, so this examination will be useful to comprehend the Kidney sicknesses effect financial and mental health of dialysis patients. Any harm which disturbs the roles of the kidneys and stops them to work normally is basically Kidney disease. In this study quantitative research method is used along with the non-probability sampling technique to collect data from the selected sample by using interview schedule and purposive and snowball sampling technique. The sample size is 200 respondents to gather the genuine information identified with this exploration from patients experiencing dialysis or kidney ailments. The Universe of this study would be the registered patients of the Liaquat National Hospital, Karachi. According to the findings dialysis really keeps the body in balance by giving it what it requires like evacuating waste, salt, and additional water from the body to cause hurt. It assists with dealing with the degree of specific synthetic substances safe in the blood like sodium, potassium and bicarbonate. It likewise controls the circulatory strain of the kidney patients.
\end{abstract}

Keywords: Kidney Disease, Dialysis, Healthcare, Quality of Life.

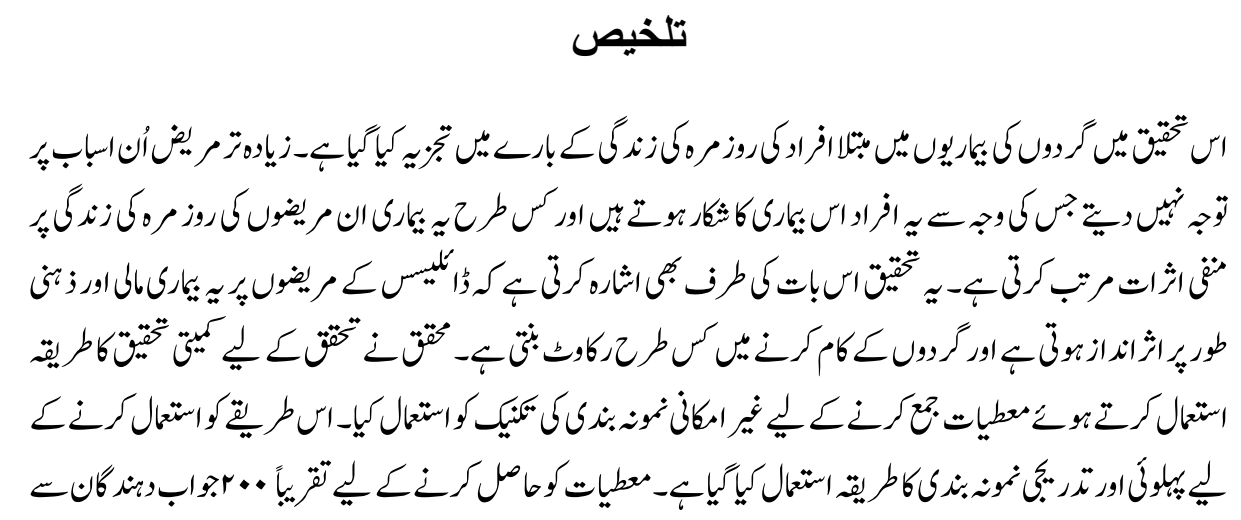




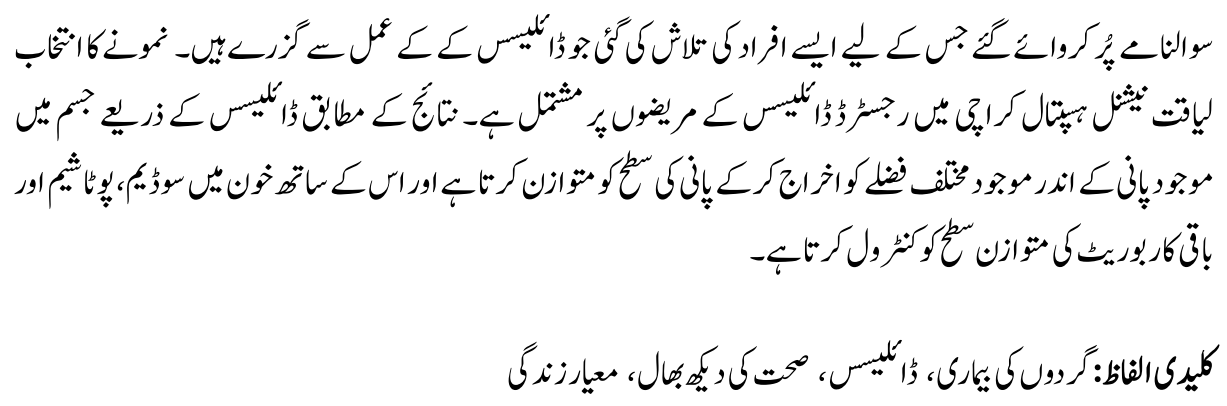

\section{Introduction}

Kidney disease has become a global concern due to its prevalence rate and increased cost of its treatment. According to estimated figures about 10.2 percent to 13 percent prevalence ranges recorded worldwide (Hallan et al., 2006). It is also observed that individual who belongs to lower social strata may suffer more as the kidney disease goes unrecognized and untreated especially in low-income and middle-income countries (Crews et al., 2014). In such circumstances many of factors have been associated with the patients which are included: no support towards healthy diets; poor physical activity; lack of healthcare information which destroy the quality life of an individual (Bruce et al., 2010).

Studies who try to build association between socio-economic status of patients, suffering from kidney disease have research limitations. As social and economic status occupy several dimensions and concepts which are incorporated with the kidney disease materials and social factors. Interestingly, it is also witnessed that this association would differ substantially and effect size region to region (Krieger et al., 1997). The study focuses on quality life of patients who are suffering from kidney diseases, and on regular dialysis treatment so, it is known that socio-economic status has no ultimate manner or degree to standardize factors of effects due to the reason various substitutes have been identified which include the patient's or family's income, educational backgrounds; of course occupations and wealth. On the other hand, the results of various studies are mainly representing their own country's statistics, because of the reason the researcher cannot generalized the results with other researches. Therefore, it is noted that the studies' results are inconsistent regarding the significance of association, it is actually difficult to understand the association between socio-economic status and kidney diseases, but this research has tried to explain the existing situation of Pakistan, who are suffering from kidney diseases while exploring their socio-economic status.

However, the statement of the research paper approaching the idea of quality of life being associated on highly subjective matters, where a person defines a quality of life as per availability of wealth; satisfaction in life; on the other hand if we see through the lens of 
healthcare then it may be viewed as multidimensional which includes physical, emotional and social well-being (Theofilou, 2013). Whereas, if a person loses a job then they may live a low quality of life. In addition, the paper is evaluating the experiences of kidney disease patients that how their lives are being hampered after they got attacked by this disease. In this regard, meta-analysis of few researches has been presented below the introductory section to make clear understanding about socio-economic factors of kidney patients and their dependence on quality of life. So, the study will be fruitful to make masses aware about Kidney diseases.

Meanwhile, in Pakistan as per estimates around 150 patients among every one million population are at end stage of renal disease (ESRD) in a year (Anees et al., 2014). As Pakistan is developing country so the services or treatment related to nephrology are under establishment. The outlay of dialysis treatment is about three thousand dollars on every single patient per annum (Naqvi, 2000). To overcome kidney disease, it is estimated that currently country has only 80 professional/trained nephrologists practitioners for over 160 million population. On the other hand, in the United States there are about 5000 nephrologists for population 300 million (Anees et al., 2014). According to the records of 2008, people who are receiving dialysis treatment are about 6000 , thus it is unveiled that only 40 percent of patients are the recipients of dialysis services in the country (Aziz, 2010). About 67 percent of patients have taken dialysis treatment every week, and it is explored that it minimized the life expectancy of about 40 percent patients to 1-2 years (Sattar et al., 2016). It also examined that quality of life of a patient affects their physical, psychological and social domains of health, as patients are experiencing life threatening disease so their expectations and perceptions changed due to their pathetic life experiences as they passing through it.

Moreover, if we talk about women specific conditions under chronic kidney disease, so women are more sensitive during their gestational periods. There are very few studies who discussed about the accurate creatinine and proteinuria ratio before and after pregnancy for all women, because if the accuracy of proteins do not identified at this stage then it is difficult to handle. Due to the reason, it needs better classification of chronic kidney disease stage. In addition, it is also suggested that kidney disease among pregnant women would have negative impacts on fertility. It is also observed that women who are conceiving with the renal diseases would have such complications such as miscarriage; preeclampsia, preterm delivery, still birth, and neonatal mortality increase with severe conditions. It is recommended by the researcher that larger prospective studies need to be confirmed in order to save the poor pregnancy outcomes (Bramham, et al., 2011).

In such circumstances the objectives have been keenly developed which are as follows:

1. To find out the relationship among the age and patient of kidney diseases.

2. To know about the economic problems and the ways to improve the quality of life. 
3. To find out the of kidney failure due to unawareness about the disease.

4. To search out the factors that can help the patients to prevent kidney failure and live a prosperous life.

5. To explore the intensity and risk of kidney disease among men and women

Later, the study is conferring the current objectives with the previous researches' observations to develop better understanding of this problem. There is one of study conducted by Vart et al., 'Mediators of the association between low socioeconomic status and chronic kidney disease in the United States' develops a relationship between the groups of lower income and of people who are suffering from chronic kidney diseases. So, it is found that people who have lower-incomes are not able to have sufficient food and nutrition's; prone to have environmental toxins; infection; and in fact low-income has created the depression and anxiety among the patients, as they are bearing all expenses of dialysis treatment and of household expenses. According to the medical practitioners, it is very alarming that inadequate and unhealthy diet likely to cause obesity, diabetes, and fuel to hypertension which are mainly responsible for harming the kidney infections and disease.

A study by Schoeni RF. et al., (2008) 'Making Americans Healthier: Social and Economic Policy as Health Policy' has explained, the lower-educational attainments are linked to kidney disease, as it associates the relationship where people have unhealthy lifestyle, are addicted to behavioral risk factors for instance: smoking, drinking alcohol, no diet plans, lower physical activity these are the major causing factors leading to secondary kidney diseases. It is discussed in the research study that there are no awareness and conscious raising curriculums in high schools even for avoiding the unhealthy life plans, to overcome on such disease at earliest. However, it is also recommended in the study that better educational attainments would lead to have improved healthcare services and can make moderate and better healthcare decisions and plans.

In few of studies, it has examined among the surveyed population that people who have lower level of occupations are more likely to work under hazardous condition, working in blue color jobs includes: labor in construction, manufacturing units, mining etc and this may create more chances among individuals to have infections in kidney and found other deteriorated health conditions (Fored CM et al., 2003). In addition, there is a probability that individuals who are suffering from hypertension and diabetes will ultimately turn to chronic kidney diseases. The study of Fitzpatrick (2001) has produced potential mechanisms for low-level occupational sectors that it resulted in fewer nephrons, or sometimes causes damage and infected tissues/cells of the kidney. It is also observed that social and economic elements also confer the health benefits, through the psycho-social mechanisms.

According to the American Kidney Fund Fighting On All Fronts, there are two major causes of kidney disease i.e. diabetes and blood pressure, patients who have these two 
diseases, should have to control their diabetes and blood pressure under doctor's consultation to avoid any of kidney disease. It is also explored that if humans keep healthy lifestyle which includes: intake of low-salt, low fat diet, daily exercise, regular checkups with doctors, prohibit smoke and tobacco, and also limits alcohol will help in controlling kidney diseases. Through taking such measures a person can live healthy and would have lesser chances of diabetes, blood pressure and chronic kidney diseases.

\section{Theoretical Framework}

There are many factors involved in the nursing care and patients outcomes of kidney disease patients. These patients face psychological and emotional issues. They need special care and needs to be treated by trained staff, because there is a chance of developing infections, excessive weight and body malaise.

\section{The Theory of Planned Behaviour}

This theory Ws originated from logical actions depending on intentional behaviour, perceptional behaviour, attitudes and social values and norms. According to Aijen, attitudes are the outcomes of one's behaviour, intentinal behaviour covers the motivation factors and influences our brhaviour (Ajzen, 1998). Whereas, Fleming highlights that social norms and values are based on people's beliefs and their social engagements. Similarly perceptional behaviour deals with the person's perceptions and it controls one's performance (Fleming, 2018). Finchman revealed the Theory of Planned Behaviour (TPB) in the self-reported treatment adherence of haemodialysis patients in the South African context as only partially applicable. The results revealed possible decreased medical complications and mortality as a result of improved adherence to the dietary and fluid restrictions among the haemodialysis population, Fincham (2008), therefore the study concluded this theory as applicable in predicting dietary and fluid adherence among haemodialysis patients.

\section{The Social Cognitive Theory}

This approach presents more of a clinical approach to health behavioural change. This approach is based on three expectancies such as situation outcome, action outcome and perceived self efficacy (Bandura, 1998). Situation outcome and action outcome are interlinked (Schwarzer, 2005). Whereas self efficacy determines whether an individual has control over their performance (Schwarzer, 2015). According to Patterson, Social Cognitive Theory explains the physical activity among dialysis patients (Patterson, 2014).

Among the patients of renal failure the key concepts related are emotional management, personal characteristics, reinforcement and expectations, behavioural capacity and self efficacy. Physical, social, cultural, economic and political factors can influence and 
predict adherence behaviours in Chronic Renal Failure patients, Baranowski (1997), and good adherence behaviours in renal failure patients can predict a reduction in complications of the disease. However, as the model has a wide-range of focus it is difficult to fully predict adherence behaviours. Currently selected parts of the theory are used and this poses questions regarding the applicability of the theory in predicting and improving adherence behaviours among patients with kidney disease.

\section{Review of Literature}

Many people face chronic diseases in the world, and they treated on regular basis. They have no choice except medicines due to seriousness of their diseases. Kidney issues are quite common in the world, especially in the Asian region due to usage of impure water. Kidney renal failure is a very dangerous and common disease of kidney. Worldwide, almost 750 million people are affected by kidney diseases (2019 World Kidney Day Editorial).

In the United States of America, 2010, people had suffered in last stage of renal disease and 415,013 were on dialysis, 27,457 Iran's people had on dialysis in 2014. (Barzegar.et.al,. 2017) As a developing country Pakistan has a large number of patients related to renal diseases. According to Pakistan Medical Association survey report 2018, twenty million patients suffering from renal disease while 20,000 patients expire every year (PMA, 2018).

Renal diseases are considered pathology with no hope for restoring health, the patients gradually with progressive evolution, trigger different reactions and compromise of the quality of life. Among the developing countries dialysis has been spread widely although it considers sensitive treatment for renal failure. The treatments of dialysis safe life of patients gives hope and increase their lives. Although this treatment could not substitute of natural and healthy process of kidneys, but the primary objective of this treatment to provide alternative function and secondary objective to well-being of the patient's life and upgrading of the quality of life. Physical, mental, social and different aspects of health are involved in quality of life. According to the World Health Organization, quality of life as a perception of an individual's life in terms of their living standard, social values, believes their expectations and goals. A person's health has an effect on individual, whole family and community as well (WHO, n.d). Many people incapable to bear medical expenses, they do not have enough money to spend healthy life and they struggle for achieving necessaries but due to the health issues specially renal diseases their expensive more increase from their earnings. Families, who belong to low income do not access to healthy food, better living environment and other facilities of life.

In developing countries, related to kidney problems and the provision of its protection are determining different factors such as socio-economic, cultural and political. These factors 
are not only found in developing countries but also exist in developed countries (Crews, Liu \& Boulware, 2014). In general, patients with CKD are affected by a wide range of physical, psychological, economic, and social problems which ultimately influence their quality of lives (Tavallaii, et al., 2009). In a study by Chow and Wong, dialysis patients had the lowest quality of life scores in terms of physical health, social function, and dimensions of CKD including job status and burden of the disease (Chow SK, and Wong FK, 2010). A studies conducted by Cleary and Drennan and Vasilieva, the mean score for physical and mental health was low and patients had poor quality of life (Cleary J., \& Drennan J, 2005, Vasilieva I A. 2006).

\section{Factors that Lead to Kidney Diseases}

Worldwide, important risk factors for kidney disease include diarrheal diseases, HIV infection, low birth weight, malaria and preterm birth, all of which are also leading global causes of dialyses. There are some other factors, which are responsible for kidney diseases such as swelling in kidney's filtering units, tubules, long blockage in urinary tract, multiple cysts, stones, cancers and infection in kidney. Diabetes, high blood pressure, cardiovascular disease, smoking, obesity, inherit and old age are also increase the risk factor of renal diseases (Luyckx, V. A., Tonelli, M. \& Stanifer, J. W., 2018). According to National Kidney Foundation, healthy living standards for fitness activities, losing weight controlled diabetic and blood pressure can be helpful to prevent and protect from kidney diseases. The Kidney can be spoiled by using drugs and overdose the pain killers. Almost $90 \%$ kidney patients has been lost kidney function at the end stage and they may occurrence weakness, vomiting, nausea, loss of hunger even difficulty in concentration (National Kidney Foundation, 2015).

Many studies have witnessed that the disease is more complicated with drug worst situation is much higher in patients with chronic kidney diseases than those without non CDK. The risk of morbidity and mortality can increase in renal patients with drugs. Most important problem in drug patients with renal destruction is inaccuracy in the medications (Long CL, Raebel MA, Price DW, Magid DJ. 2004, Manley HJ, Cannella CA, Bailie GR, St Peter WL. 2005). According to the American Society of Nephrology 2018, many factors are responsible for kidney diseases along life style different types of drugs like alcohol, heroin, tobacco smoking, marijuana (chars) cocaine etc, also contributing and increasing the risk of death (Joshua D. Bundy et al, 2018).

Saeed et al., (2017) found in the study that most effected age group was 46 to 60 and 30 to 45 and the most important contributing factor of the end-stage of renal diseases was hypertension. The study further stated that dialysis patient's physical health steadily turn down (Saeed et al., 2017). Similar facts highlighted by Jessani et al. 2014, that 40years or

older more affected age group were CKD in Karachi, Pakistan (Jessani et al. 2014). 
Khuram, Asifa, et al in 2015, explored the similar facts that hypertension is very high risk factor for renal diseases. In Pakistan CKD is very high rate as compared to other countries and faced financial burden while effect on morbidity and loss of life (Khuram, et al., 2015).

\section{Social and Economical Effects}

The study explored that income and health connect to each other and access to better health facilities with higher income, however people with poor health and any disability can make it difficult to achieve education and get keep hold of good and highly-paid employment (Center on Society and Health, 2015). Almost all dialysis patients lose their job or have decreased income, which results in financial problems, reduced their living standard and change quality of life (Costa,et.al. (2016). Many patients do not have the ability to cope up with physical and psychological disabilities, which influence the patient's life and affect the quality of life, thus affecting economic development of a person, family and country as well, whereas, high income directly influences better health and quality of life. Rich people can easily afford expensive treatment, access to better facilities, speedy recovery and improved health (Center on Society and Health, 2015).

\section{Physical and Psychological Effects}

Renal diseases have multiple problems having both physical and psychological effects on patient's life. Patients cannot survive without medicines, dialysis, doctors, hospitals, machines and care takers. Patients are totally dependent on these care factors and they feel helpless without proper care. The process of dialysis is extremely stress full and time taking procedure (Frazao et al., 2014). Depression and delirium among renal diseases patients is most common psychotic complication, while suicide rates have higher than the healthy persons (Gerogianni \& Babatsikou, 2014). Palpitations, chest pain, sweating and fear of dying are the symptoms of extreme anxiety but many times these symptoms are not considering with anxiety and patients too angry if doctor suggested psychotherapy.

In our planet half of the population consists on Women, who play an important role in their families and societies. Unfortunately in many areas of the world they do not have access to basic needs especially health care facilities similarly still remain in health research studies due to unseen socio-cultural boundaries. Limited studies available related to women's health and kidney diseases. Kidney patient women have more risk of heart diseases than non chronic kidney patients but still have lower risk than men. Renal diseases are not favorable for pregnancy, sometimes symptoms appeared in early stages and during pregnancy women have a risk for kidney injuries (Piccoli, et al., 2015).

CKD and transplantation are also effect fertility. Although the hope of life is increased through renal replacement therapy (RRT), including dialysis and transplantation but all 
patients did not access to health care facilities, particularly women and girls due to their socio-cultural environment and gender discrimination. Between sexes socio economic factor also a major contributor in the inequality in low income communities. Although mortality rate are more or less same in male and female but morbidity rate is higher in female (Adams, et al., 2017).

\section{Methodology}

In this study quantitative research method is used along with the non-probability sampling technique to collect data from the selected sample by using interview schedule and purposive and snowball sampling technique. The sample size is 200 respondents to gather the genuine information identified with this exploration from patients experiencing dialysis or kidney ailments. The Universe of this study would be the registered patients of the Liaquat National Hospital, Karachi for the treatment as kidneys patients. Sampling is a strategy of picking trial of the masses. It is a subset, containing the properties of greater masses. Tests are used in quantifiable testing when masses sizes are preposterously gigantic for the test to join each possible part or recognitions.

\section{Data Analysis}

The data was analyzed in segments systematically. First the interview schedule (in Urdu language) was used to record the response of the respondents. Secondly the responses were translated from Urdu to English. Later it was presented in forms of case studies to have in-depth information on the subject.

\section{Purpose of the Study}

The main aim of the present study is to have quantitative analysis regarding the quality of life of dialysis patients with kidney diseases. Exploring the exclusive dimensions of kidney diseases and issues which are not yet explored, because there is no sufficient research work done regarding the subject.

\section{Results and Discussion}

This study analyzes the level of quality of life of dialysis patients with kidney disease (male and female). The report is based on the interviews conducted with a total number of 200 male and female patients. All these patients were interviewed using abusive language. According to the findings of the study data shows that mean age of participants is $44.11 \pm 19.00$ years ranging from 12 years to 85 years while graphs showing frequency distribution of age (Table -1). The data shows that among total 200 respondents; $47.5 \%$ of the respondents are male and $52.5 \%$ of respondents are female (Table -2$)$. As per data 
out of total 200 respondents; $75 \%$ of the respondents are uneducated. $50 \%$ of the respondents are educated (Table -3 ). The figure clearly shows that out of total 200 respondents; $27 \%$ of the respondents have no income, $18 \%$ of the respondents have income between 1,000 to $15,000,23.5 \%$ of the respondents have income between 16,000 to $30,000,15.5 \%$ of the respondents have income between 31,000 to $45,000,11.5 \%$ of the respondents have income between 46,000 to $60,000,4.5 \%$ of the respondents have income of 61,000 and above (Table -4). Similarly out of total 200 respondents; $52 \%$ of the respondents think that disease has affected economical condition of their life and $48 \%$ of the respondents think that disease has not affected economical condition of their life (Table -4.1).

As per data out of total 104 respondents; $32.7 \%$ of the respondents think that disease has effected economical condition of their life because they are the only bread earner for their family, $61.5 \%$ of the respondents think that disease has effected economical condition of their life because it's their responsibility to fulfill all needs and 5.8\% of the respondents have not responded to the question (Table -4.2). it also shows that out of total 96 respondents; $30.2 \%$ of the respondents think that disease has not affected economic condition of their life because family help them economically, $8.3 \%$ of the respondents think that disease has not affected economic condition of their life because they do not take it their own responsibility and $61.5 \%$ of the respondents have not responded to the question (Table - 5). Data has shown that out of total 200 respondents; $14.0 \%$ of the respondent's use drugs and $86 \%$ of the respondent's not use drugs (Table - 6). When asked about the use of drugs out of total 28 respondents $17.9 \%$ of the respondents using drug due to tension, $39.3 \%$ of the respondents using drug because having addiction with friends gathering, $17.9 \%$ of the respondents using drug because having addiction by child hood, $7.1 \%$ of the respondents using drug because they catch it from parents, $10.7 \%$ of the respondents using drug due to avoid loneliness and $7.1 \%$ of the respondents have not responded to the question (Table - 6.1). similarly out of total 172 respondents; $52.3 \%$ of the respondents not using drug because they are against drug $33.7 \%$ of the respondents not using drug because they never want to take it, $11.0 \%$ of the respondents not using drug because not allowed by parents, $1.2 \%$ of the respondents not using drug because of fear of disease and $1.7 \%$ of the respondents not using drug they are allergic to any sort of drug (Table - 6.2). These figures identified that reasons of their disease out of 200 respondents are as follows $41 \%$ of the respondents think unhygienic water is the reason of their disease, $18 \%$ of the respondents think unhygienic food is the reason of their disease, $13 \%$ of the respondents think family history is the reason of their disease, $12 \%$ of the respondents think wrong medication is the reason of their disease, $12.5 \%$ of the respondents think tension is the reason of their disease and $3.5 \%$ of the respondents didn't responded to the question (Table - 7). Regarding treatment the respondents claim that Breathing problem, family disturbances and expensive treatment are the three major problem for $18 \%$ of respondents, Diabetes, hair loss and depression are the three major 
problem for $8 \%$ of respondents, Financial issues, expensive medication and expensive treatment are the three major problem for 33\% of respondents, Food, medicine and bad water are the three major problem for $2 \%$ of respondents, High blood pressure, stroke and fast heart beat are the three major problem for $4 \%$ of respondents, Lack of sleep, high blood pressure and breathing problem are the three major problem for $3.5 \%$ of respondents, Medicine, transport and take care are the three major problem for $4 \%$ of respondents, No hope from life, sugar and stress are the three major problem for $2 \%$ of respondents, Pain in foot, problem in waking and mental stress are the three major problem for $8 \%$ of respondents, Social life, psychiatric issues and fear of losing life are the three major problem for $3.5 \%$ of respondents, Stagnant water, Poor diet and unhealthy food are the three major problem for $6 \%$ of respondents, Stress, family disturb and not pass urine are the three major problem for $1 \%$ of respondents and weakness, pain in bones and tiredness are the three major problem for $7 \%$ of respondents (Table - 8). The results show that out of 200 respondents $45.5 \%$ of the respondents face financially trouble because of disease, $43.5 \%$ of the respondents face mentally stress trouble because of disease, $8.5 \%$ of the respondents face other trouble because of disease and $2.5 \%$ of the respondents have not responded to the question (Table - 9).

Similarly regarding help in treatment 200 respondents claim that $82 \%$ of respondents thinks government should provide financial help for dialysis patients, $11 \%$ of respondents thinks government should provide free medical treatment for dialysis patients, $1 \%$ of respondents thinks government should provide free dialysis for dialysis patients, $3.5 \%$ of respondents thinks government should organized awareness seminars and $2.5 \%$ of the respondents didn't respond to question (Table - 10). Whereas, out of 200 respondents thinks that $4 \%$ of respondents thinks government should help by arranging seminars, $4 \%$ of respondents thinks government should help by charges reduction, $1 \%$ of respondents thinks government should help by providing clean water, $49.5 \%$ of respondents thinks government should help by providing financial help, $2 \%$ of respondents thinks government should help by providing free dialysis, $27.5 \%$ of respondents thinks government should help by providing free treatment, $1 \%$ of respondents thinks government should help by providing free medicines, $10 \%$ of respondents thinks government should help by providing good treatment and $1 \%$ of respondents thinks government should help by making proper policy (Table -11).

\section{Conclusions}

The research problem focuses on the psychological impact and socio-economic issues of dialysis patients going under treatment. These patients usually suffer from stress, depression due to many factors like financial issues. Dialysis treatment is very sensitive and expensive which impacts their lives emotionally as well. They need special care from their family, especially women, because they become more dependent on their families. Therefore, it is needed to counsel families and attendants to make them understand the 
physical and mental state of their patient, so that they can deal with them easily and can help them to come out of the depression phase to lead a happy and stress free life.

Kidneys function as a filter to our body and when it starts mal-functioning human body stops working properly. Patients with kidney disease face many problems like economic, social and psychological issues and it completely transforms human psyche. The cost of treatment is very high most of the patients seek help of social service care givers. Funds are scarce not every patient can avail social services support This study has focused on the relation between the age and the patient's condition of the male and female kidney disease patients and to find out the main causes of kidney diseases. There are a number of psychological problems the people are going through that researcher wanted to find out and needed to know about that. Basically researcher wanted to know about the factors which could be helpful to prevent the kidney problems among the individuals and aware others to make sure they don't become the victim of that life threatening and changing disease. People going through dialysis go from a good healthy family to a normal unhealthy kind of family as dialysis takes all their time and money just to make them live a few extra years. They have to sacrifice their own family's future. The people with such position go through some serious hell as their personal life is deeply damaged and they have to be assuring of what they would be able to do of their lives and of their loved ones lives. The people can be really mean at times and can be really disturbing with the society making it hard for them to survive and go towards suicide. As in their opinion suicide is the only option they seek, which is quick and will ease them from some serious pain. At the end researcher would like to suggest that some serious preventive measures can be taken for the patients, so that they don't have to go through the seriousness of the disease. From the early stage and for those who are going towards it somehow. People should be given awareness on all their steps of life, they should be aware of the things that can happen to them if they don't take care of themselves. The patients are normally socioeconomically and psychologically disturbed so the social workers should play their part here and counsel them as necessary in their different phases of life. Along with them their families and people to whom they are dependent to need some serious amount of counseling as they are the one bearing their patient's mood swings, especially for women, because they face more problems and suffer more than men.

Female patients claim that they desire to control time and place of dialysis treatment for making the procedure easy and to deal with their daily routines. They go through emotional turmoil during the treatment, if they do not find the support of physicians, nursing staff and family. Among the dialysis patients usually women depend on their physician to decide things regarding their disease. It is very important to that medical staff and doctors should be very supportive and caring to help patients to cope up with the overwhelming and difficult phase of their life due to the treatment of dialysis. 


\section{References}

Adams, S.V., Rivara, M., Streja, E., et al. (2017). Sex Differences in Hospitalizations with Maintenance Hemodialysis, J Am Soc Nephrol, vol.28, pp.2721-2728.

Ajzen, I. (1998). Models of Human Social Behavior and their Application to Health Psychology, Psychol Heal, vol.13, pp.735-9.

American Kidney Fund Fighting On All Fronts: Retrieve from https://www.kidneyfund.org/ kidney-disease/chronic-kidney-disease-ckd/, on November 28, 2019.

Anees, M., Ibrahim, M., Adhmi, S. \& Nazir, M. (2014). Comparison Of Awareness About Nephrology And Kidney Diseases Amongst Doctors In Institutes With And Without Nephrology Departments, Pakistan Journal of Medical Sciences, vol.30, pp.891-894.

Aziz, Umair (2010, December 21). Too Few Machines, Too Many Dialysis Patients, Pakistan Today. Retrieve from https://www.pakistantoday.com.pk/2010/12/21/ too-few-machines-too-many-dialysis-patients/ on December 5, 2019.

Bandura, A. (1998). Health Promotion from the Perspective of Social Cognitive Theory, Psychol Heal, vol.13, pp.623-49.

Baranowski T., Lin L., Wetter D., Resnicow K. \& Hearn, M. (1997). Theory As Mediating Variables: Why Aren't Community Interventions Working As Desired? Ann Epidemiol, vol.7, pp.89-95.

Barzegar, H., Jafari, H., Yazdani, Charati \& J., Esmaeili R.(2017). Relationship Between Duration of Dialysis and Quality of Life in Hemodialysis Patients, Iran $J$ Psychiatry Behav Sci., vol.11:4, p.e6409.

Bramham, K., Briley, L. A., Seed, T. P., Poston, L., Shennan, H. A. \& Chappell, C. L. (2011). Pregnancy Outcomes In Women With Chronic Kidney Disease: A Prospective Cohort Study, Sage Publication, https://www.researchgate.net/ profile/Paul_Seed/publication/49802356_Pregnancy_Outcome_in_Women_with_ Chronic_Kidney_Disease_A_Prospective_Cohort_Study/links/0912f4fa2ce-1950 a8000000.pdf, Retrieve on December 12, 2019.

Bruce, M.A., Beech, B.M., Crook ED et al. (2010). Association of Socioeconomic Status and CKD among African Americans: The Jackson Heart Study, American Journal of Kidney Disease, vol.55, pp.1001-1008. Retrieve from https://www.sciencedirect.com/ science/article/abs/pii/S0272638610004841 on December 5, 2019. 
Chow, S.K. \& Wong, F.K. (2010). Health-Related Quality Of Life In Patients Undergoing Peritoneal Dialysis: Effects Of A Nurse-Led Case Management Programme, $J$ Adv Nurs, vol.66, pp.1780-92.

Cleary, J. and Drennan, J. (2005).Quality Of Life Of Patients On Haemodialysis For End-Stage Renal Disease, J Adv Nurs, vol.51, pp.577-86.

Crews, D.C., Liu Y. \& Boulware, L.E. (2014). Disparities In The Burden, Outcomes, And Care Of Chronic Kidney Disease, Curr Opin Nephrol Hypertens, vol.14:23, pp.298-305.

Crews, D.C., Gutiérrez, O.M., Fedewa, S.A. et al., (2014). Low Income, Community Poverty And Risk Of End Stage Renal Disease, BMC Nephrology, vol(15) retrieve from https://bmcnephrol.biomedcentral.com/articles/10.1186/1471-236915-192\#citeas on December 5, 2019.

Fleming, M., Bapat, S. \& Varisco, T. (2018). Using The Theory Of Planned Behavior To Investigate Community Pharmacists' Beliefs Regarding Engaging Patients About Prescription Drug Misuse, Res Soc Adm Pharm.

Fored, C.M., Ejerblad, E., Fryzek, JP. et al. (2003). Socio-Economic Status And Chronic Renal Failure: A Population Based Case-Control Study In Sweden, Nephrol Dial Transplant.

Frazão, C. M., de Sá, J. D., Medeiros, A. B., Fernandes, M. I., Lira, A. L. \& Lopes, M. V. (2014). The Adaptation Problems Of Patients Undergoing Hemodialysis: SocioEconomic and Clinical Aspects. Rev Lat Am Enfermagem, vol.22:6, pp.966-972.

Hallan, S.I., Coresh J., Astor B.C. \& et al. (2006). International Comparison of the Relationship of Chronic Disease Prevalence and ESRD Risk, Journal of the American Society of Nephrology, vol.17:8, pp.2275-2284.

Jessani, et al. (2014). Prevalence, Determinants and Management of Chronic Kidney Disease in Karachi, Pakistan-A Community Based Cross-Sectional Study, BMC Nephrology, vol.15(90), http://www.biomedcentral.com/1471-2369/15/90.

Khuram, et al. (2015). To Assess and Evaluate the Risk Factors Associated with Chronic Kidney Diseases in Karachi, Pakistan, A cross sectional study, $P J M H S$, vol.9:4, pp.1226-1228. 
Krieger, N., Williams, D.R. \& Moss, N.E. (1997). Measuring Social Class in US Public Health Research: Concepts, Methodologies and Guidelines, Annual Review of Public Health, vol.18, pp. 341-378.

Long, C.L., Raebel, M.A., Price, D.W. \& Magid, D.J. (2004). Compliance with Dosing Guidelines in Patients with Chronic Kidney Disease, Ann Pharmacother, vol. 38, pp.853-8.

Luyckx, V. A., Tonelli, M., \& Stanifer, J. W. (2018). The global burden of kidney disease and the sustainable development goals, Bulletin of the World Health Organization, vol.96:6, pp.414-422.

Manley, H.J., Cannella, C.A., Bailie, G.R. \& St Peter W.L. (2005). Medication-Related Problems In Ambulatory Hemodialysis Patients: A Pooled Analysis, Am J Kidney Dis, vol.46, pp.669-80.

Naqvi, Saiyid A.J. (2000). Nephrology Services in Pakistan, Nephrology Dialysis Transplantation, vol.(15) pp.769-771. Retrieve from https://academic.oup.com/ ndt/article/15/6/769/1858457 on December 5, 2019.

National Kidney Foundation (2015). Kidney Disease: Causes. Retrieved from https://www.kidney.org/atoz/content/kidneydiscauses. December 01, 2019.

Pakistan Today. (2018). 20m People Suffer From Kidney Diseases In Pakistan: PMA, Karachi, Pakistan, Retrieved on December, $1^{\text {st }}$ 2019, https://www.pakistantoday.com.pk/2018/03/07/20m-people-suffer-from-kidneydiseases-in-pakistan-pma/

Patterson, M., Umstattd, Meyer M., Beaujean A. \& Bowden, R. (2014). Using the Social Cognitive Theory to Understand Physical Activity among Dialysis Patients, Rehabil Psychol, vol.59, p.278.

Piccoli, G.B., Cabiddu, G, Attini, R. et al. (2015). Risk of Adverse Pregnancy Outcomes in Women with CKD, J Am Soc Nephrol, vol.26, pp.2011-2022.

Saeed et al. (2017). Chronic Kidney Diseases- A Multi-Center Study in Karachi, Pakistan, International Journal of Pharmacy and Pharmaceutical Sciences, vol.9:12, pp.170-174. 
Sattar, S., Khan, N., Ahmad, F., Adnan, F. \& Danish, S. (2016). Post-Dialysis Effects in Patients on Haemodialysis, Journal of the Pakistan Medical Association, vol.66, Retrieve from https://jpma.org.pk/article-details/7808 on December 5, 2019.

Schwarzer, R. \& Luszczynska, A. (2015). Social Cognitive Theory. Predicting Health Behaviour, vol.1, pp.127-69.

Schwarzer, R. \& Luszczynska, A. (2015).Self-Beliefs and Self-Regulation in Health Behavior Change. Self-Concept, Motivation and Identity: Underpinning Success with Research and Practice.

Tavallaii, et al. (2009). Socioeconomic Links to Health-Related Quality of Life, Anxiety and Depression in Kidney Transplant Recipients, Iran J Kidney Dis, vol.3, pp.40-4.

Theofilou, Paraskevi (2013). Theoretical Contributions: Quality of Life: Definitions and Measurement, Europe Journal of Psychology, vol.91, p.151.

Vart, p., Gansevoort, R., Crews, D., Reijneveld, S. \& Bultmann, U. (2015). Mediators of the Association Between Low Socioeconomic Status and Chronic Kidney Disease in the United States, American Journal of Epidemiology, vol.181:6, pp.385-396.

WHO (n.d). WHOQOL: Measuring Quality of Life, WHOQOL: Measuring Quality of Life, Retrieved on December $1^{\text {st }} 2019$, https://www.who.int/healthinfo/survey/ whoqol-qualityoflife/en/

World Kidney Day Editorial (2019). Burden, Access and Disparities in Kidney Disease, World Kidney Day Editorial. 


\section{Annex}

Table - 1

Frequency distribution according to the descriptive statistics of age (years)

\begin{tabular}{|c|c|c|}
\hline \multicolumn{2}{|l|}{ (n) } & Statistic \\
\hline \multirow[t]{7}{*}{ Age (years) } & Mean & 44.1150 \\
\hline & Median & 45.0000 \\
\hline & Variance & 361.369 \\
\hline & Std. Deviation & 19.00970 \\
\hline & Minimum & 12.00 \\
\hline & Maximum & 85.00 \\
\hline & Range & 73.00 \\
\hline
\end{tabular}

Table -2

Frequency distribution according to the gender

\begin{tabular}{|l|c|c|}
\hline & Frequency & Percent \\
\hline Male & 95 & 47.5 \\
\hline Female & 105 & 52.5 \\
\hline Total & 200 & 100.0 \\
\hline
\end{tabular}

Table $-\mathbf{3}$

Frequency distribution according to the education

\begin{tabular}{|l|c|c|}
\hline & Frequency & Percent \\
\hline Educated & 150 & 75.0 \\
\hline Uneducated & 50 & 25.0 \\
\hline Total & 200 & 100.0 \\
\hline
\end{tabular}

Table -4

Frequency distribution according to the income

\begin{tabular}{|l|c|c|}
\hline & Frequency & Percent \\
\hline None & 54 & 27.0 \\
\hline 1,000 to 15,000 & 36 & 18.0 \\
\hline $16,000-30,000$ & 47 & 23.5 \\
\hline $31,000-45,000$ & 31 & 15.5 \\
\hline $46,000-60,000$ & 23 & 11.5 \\
\hline 61,000 and Above & 9 & 4.5 \\
\hline Total & 200 & 100.0 \\
\hline
\end{tabular}


Table -5

Frequency distribution according to the do you know this disease has affected economic condition of your life?

\begin{tabular}{|l|c|c|}
\hline & Frequency & Percent \\
\hline Yes & 104 & 52.0 \\
\hline No & 96 & 48.0 \\
\hline Total & 200 & 100.0 \\
\hline
\end{tabular}

Table -5.1

Frequency distribution according to if yes how?

\begin{tabular}{|c|c|c|c|}
\hline \multicolumn{2}{|c|}{$\begin{array}{l}\text { Do you know this disease has effected economical } \\
\text { condition of your life? }\end{array}$} & Frequency & Percent \\
\hline \multirow[t]{4}{*}{ Yes } & I am the only bread earner for my family & 34 & 32.7 \\
\hline & It's my responsibility to fulfill all needs, & 64 & 61.5 \\
\hline & No answer & 6 & 5.8 \\
\hline & Total & 104 & 100.0 \\
\hline
\end{tabular}

Table -5.2

Frequency distribution according to the If no then how?

\begin{tabular}{|l|l|l} 
Do you know this disease has effected economical condition & Frequency & Percent
\end{tabular} of your life?

\begin{tabular}{l|l} 
No & Because the family help me economically,
\end{tabular} Because they do not take it their own responsibility

No Answer

Total

\begin{tabular}{|c|c|}
\hline 29 & 30.2 \\
\hline 8 & 8.3 \\
\hline 59 & 61.5 \\
\hline 96 & 100.0 \\
\hline
\end{tabular}

Table -6

Frequency distribution according to the do you take any drugs?

\begin{tabular}{|l|c|c|}
\hline & Frequency & Percent \\
\hline Yes & 28 & 14.0 \\
\hline No & 172 & 86.0 \\
\hline Total & 200 & 100.0 \\
\hline
\end{tabular}

Table -6.1

Frequency distribution according to the if yes then reason?

\begin{tabular}{|l|l|c|c|}
\hline \multicolumn{2}{|c|}{ Do you take any drugs? } & Frequency & Percent \\
\hline \multirow{4}{*}{ Yes } & Due to Tension & 5 & 17.9 \\
\cline { 2 - 4 } & Having addiction with friends gathering & 11 & 39.3 \\
\cline { 2 - 4 } & Addiction by child hood & 5 & 17.9 \\
\cline { 2 - 4 } & catch it from parents & 2 & 7.1 \\
\cline { 2 - 4 } & to avoid loneliness & 3 & 10.7 \\
\cline { 2 - 4 } & No answer & 2 & 7.1 \\
\cline { 2 - 4 } & Total & 28 & 100.0 \\
\hline
\end{tabular}


Table -6.2

Frequency distribution according to if no then why?

\begin{tabular}{|l|l|c|c|}
\hline \multicolumn{2}{|l|}{ Do you take any drugs? } & Frequency & Percent \\
\hline \multirow{4}{*}{ No } & Against the drug & 90 & 52.3 \\
\cline { 2 - 4 } & Never want to take it & 58 & 33.7 \\
\cline { 2 - 4 } & Parents not allowed & 19 & 11.0 \\
\cline { 2 - 4 } & Fear of any disease & 2 & 1.2 \\
\cline { 2 - 4 } & allergic to any sort of drug & 3 & 1.7 \\
\cline { 2 - 4 } & Total & 172 & 100.0 \\
\hline
\end{tabular}

Table -7

Frequency distribution according to what do you think what is the reason of your disease?

\begin{tabular}{|l|c|c|}
\hline & Frequency & Percent \\
\hline unhygienic water & 82 & 41.0 \\
\hline unhygienic food, & 36 & 18.0 \\
\hline family history & 26 & 13.0 \\
\hline wrong medication & 24 & 12.0 \\
\hline tension & 25 & 12.5 \\
\hline No Answer & 7 & 3.5 \\
\hline Total & 200 & 100.0 \\
\hline
\end{tabular}

Table -8

Frequency distribution according to the describe three major problem of your disease?

\begin{tabular}{|l|c|c|}
\hline & Frequency & Percent \\
\hline Breathing Problem, family disturb, expensive treatment & 36 & 18.0 \\
\hline diabetes, hairless, depression & 16 & 8.0 \\
\hline Financial Issues, expensive medication, expensive treatment & 66 & 33.0 \\
\hline Food, Medicine, Bad Water & 4 & 2.0 \\
\hline High BP, Stroke, Fast Heart beat & 8 & 4.0 \\
\hline Lack of Sleep, High BP, Breathing Problem & 7 & 3.5 \\
\hline Medicine, Transport, Take care & 8 & 4.0 \\
\hline No hope from life, Sugar, Stress & 4 & 2.0 \\
\hline Pain in Foot, Problem in waking, mental stress & 16 & 8.0 \\
\hline Social Life, Psychiatric issues, Fear of losing life & 7 & 3.5 \\
\hline Stagnant Water, Poor Diet, Unhealthy food & 12 & 6.0 \\
\hline Stress, family disturb, not pass urine & 2 & 1.0 \\
\hline Weakness, pain in bones, tiredness & 14 & 7.0 \\
\hline Total & 200 & 100.0 \\
\hline
\end{tabular}


Table -9

Frequency distribution according to the What troubles, did your family face regarding your disease?

\begin{tabular}{|l|c|c|}
\hline & Frequency & Percent \\
\hline Financial problem, & 91 & 45.5 \\
\hline Mental stress & 87 & 43.5 \\
\hline Social problem & 17 & 8.5 \\
\hline No Answer & 5 & 2.5 \\
\hline Total & 200 & 100.0 \\
\hline
\end{tabular}

Table -10

Frequency distribution according to the What measures government should take for dialysis patients?

\begin{tabular}{|l|c|c|}
\hline & Frequency & Percent \\
\hline Financial help & 164 & 82.0 \\
\hline free medical treatment, & 22 & 11.0 \\
\hline free dialysis & 2 & 1.0 \\
\hline awareness seminars & 7 & 3.5 \\
\hline No answer & 5 & 2.5 \\
\hline Total & 200 & 100.0 \\
\hline
\end{tabular}

Table - 11

Frequency distribution according to how should be government help?

\begin{tabular}{|l|c|c|}
\hline & Frequency & Percent \\
\hline Arrange Seminar & 8 & 4.0 \\
\hline Charges should be reduce & 8 & 4.0 \\
\hline Clean water & 2 & 1.0 \\
\hline Financial Support & 99 & 49.5 \\
\hline Free Dialysis & 4 & 2.0 \\
\hline Free Treatment & 55 & 27.5 \\
\hline Provide Free Medicine & 2 & 1.0 \\
\hline Provide Good treatment & 20 & 10.0 \\
\hline To make the proper policy & 2 & 1.0 \\
\hline Total & 200 & 100.0 \\
\hline
\end{tabular}

Aqeel Haider is Ph.D Scholar in the Department of Social Work, University of Karachi, Karachi, Pakistan.

Dr. Nasreen Aslam Shah is Dean, Faculty of Arts and Social Sciences, University of Karachi, Meritorious Professor in the Department of Social Work and Director, Centre of Excellence for Women's Studies, University of Karachi, Karachi, Pakistan.

Dr. Muhammad Shahid is Chairman and Associate Professor in the Department of Social Work, University of Karachi. 